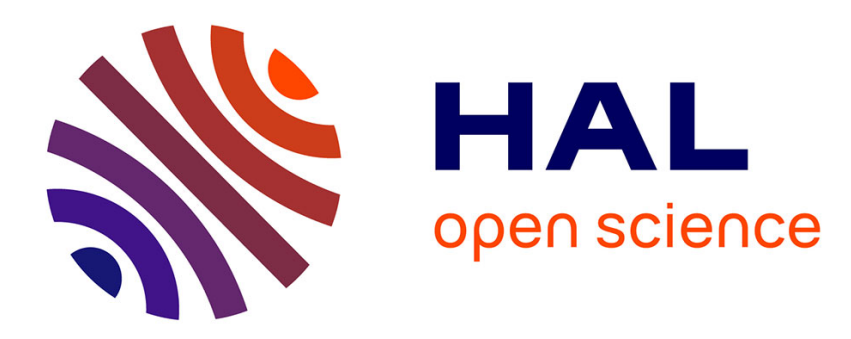

\title{
A survey of isotropic and anisotropic modifications of the refractive index
}

\author{
H. Hoffmann
}

\section{To cite this version:}

H. Hoffmann. A survey of isotropic and anisotropic modifications of the refractive index. Journal de Physique IV Proceedings, 1992, 02 (C2), pp.C2-21-C2-30. 10.1051/jp4:1992203 • jpa-00251274

\section{HAL Id: jpa-00251274 https://hal.science/jpa-00251274}

Submitted on 1 Jan 1992

HAL is a multi-disciplinary open access archive for the deposit and dissemination of scientific research documents, whether they are published or not. The documents may come from teaching and research institutions in France or abroad, or from public or private research centers.
L'archive ouverte pluridisciplinaire HAL, est destinée au dépôt et à la diffusion de documents scientifiques de niveau recherche, publiés ou non, émanant des établissements d'enseignement et de recherche français ou étrangers, des laboratoires publics ou privés. 


\title{
A survey of isotropic and anisotropic modifications of the refractive index
}

\author{
H. J. HOFFMANN \\ Schott Glaswerke, Central Research and Development Division, Hattenbergstrasse 10, 6500 Mainz, \\ Germany
}

\begin{abstract}
The effects causing differential modifications of the refractive index $n(\lambda)$ are discussed. Isotropic changes are induced by the variation of the temperature and of the annealing schedule. Anisotropic changes can be caused by mechanical stresses and electric or magnetic fields. Simple dispersion formulae have been derived successfully on the basis of a one-term Sellmeier equation. It is shown that the experimental data can be fitted by these formulae. Further possibilities to vary $n(\lambda)$ are mentioned.

Résumé: On discute des effets à l'origine des modifications differentielles de l'indice de réfraction $\mathrm{n}(\lambda)$. Des changements isotropes sont induits par la température ou le cycle de recuit. Des changements anisotropes peuvent être dîs aux contraintes mécaniques ou aux champs électriques et magnétiques. Des formules simples de dispersion ont été obtenues avec succès sur la base de l'équation à un-terme de Sellmeier. On montre que les données expérimentales peuvent être ajustées par ces formules. On mentionne aussi d'autres possibilités pour faire varier $n(\lambda)$.
\end{abstract}

\section{Introduction}

Optical glasses used for transmissive optical elements are characterized by their refractive index $\mathrm{n}$ as a function of the wavelength $\lambda$. Several dispersion formulae are known to decribe $\mathrm{n}(\lambda)$. In the following, however, special reference is made to the Sellmeier equation

$$
\mathrm{n}^{2}(\lambda)-1=\mathrm{a}_{\mathrm{s}} \sum_{\mathrm{i}=1}^{\mathrm{m}} \frac{\mathrm{N}_{\mathrm{i}}}{\mathrm{V}} \mathrm{f}_{\mathrm{i}} \frac{\lambda^{2} \cdot \lambda_{0 \mathrm{i}}{ }^{2}}{\lambda^{2}-\lambda_{0 \mathrm{i}}{ }^{2}}
$$

wherein the optical polarizability $\mathrm{n}^{2}(\lambda)-1$ is given by a superposition of a series of oscillator terms without damping. (Therefore it applies only in the case when absorption can be neglected.)

Each term (index i) on the right-hand side of (1) is characterized by the number of oscillators $\mathrm{N}_{i}$ per volume $V$, the oscillator strength $f_{i}$, and the resonance wavelength $\lambda_{0 i}$. In many cases, three terms in (1) are sufficient to describe $n(\lambda)$ to 6 decimal places in the spectral range from the near ultraviolet to the near infrared.

Generally, $n(\lambda)$ is a function of the chemical composition of the glasses. In the present article, however, we do not focus on the chemical trends of the refractive index and its dispersion and the corresponding modifications.

In optical applications, the effective refractive index refers to the ambient medium, which is very often air. This relative index is given by

$$
\mathrm{n}_{\mathrm{rel}}=\mathrm{n}_{\mathrm{abs}} / \mathrm{n}_{\mathrm{med}}
$$


wherein $n_{a b s}$ and $n_{m e d}$ are the refractive indices of the glass and the ambient medium with respect to vacuum. In the following we will use $n$ instead of $n_{a b s}$ for short and we will consider how $n_{a b s}$ is modified by variables which are accessible externally.

\section{Temperature coefficient of the refractive index (thermo-optic coefficient)}

The data of $n(\lambda)$ in the catalogues of optical glasses refer to $20^{\circ} \mathrm{C}$ [1]. Since $n(\lambda)$ varies with the temperature $\mathrm{T}$, one is interested to characterize the stability of $n(\lambda)$ with respect to variations of $T$. Until recently, this has been done by the average temperature coefficients of the refractive index (thermo-optic coefficient) for a set of discrete wavelengths $\lambda_{\mathbf{k}}$ and temperature intervals $\left(T_{j+1}, T_{j}\right)$. These average temperature coefficients are defined by

$$
\frac{\Delta \mathrm{n}\left(\lambda_{\mathrm{k}}, \mathrm{T}_{\mathrm{j}+1, j}\right)}{\Delta \mathrm{T}_{\mathrm{j}+1, j}}=\frac{\mathrm{n}\left(\lambda_{\mathrm{k}}, \mathrm{T}_{\mathrm{j}+1}\right)-\mathrm{n}\left(\lambda_{\mathrm{k}}, \mathrm{T}_{\mathrm{j}}\right)}{\mathrm{T}_{\mathrm{j}+1}-\mathrm{T}_{\mathrm{j}}}
$$

On the other hand, a dispersion formula for the temperature coefficient $\frac{\operatorname{dn}(\lambda, T)}{d T}$ is very useful for calculations. In principle, it is possible to consider the fitting parameters $\lambda_{0 i}$ and

$$
A_{i}=a_{s} \frac{N_{i}}{V} f_{i}
$$

as a function of the temperature. Using three oscillator terms and expanding the fitting parameters $\lambda_{0 \mathrm{i}}$ and $\mathrm{A}_{\mathrm{i}}(\mathrm{i}=1,2,3)$ to a polynomial of second order, however, requires too many fitting parameters. Since one considers small variations $\Delta n$ with respect to the dispersion $n(\lambda)$ at the reference temperature $\mathrm{T}=20^{\circ} \mathrm{C}$, one can use a simplified dispersion formula, namely a one-term Sellmeier equation

$$
\mathrm{n}^{2}(\lambda)-1=\mathrm{a}_{\mathrm{s}} \frac{\mathrm{N}}{\mathrm{V}} \mathrm{f} \frac{\lambda^{2} \cdot \lambda_{0}^{2}}{\lambda^{2}-\lambda_{0}{ }^{2}}
$$

with suitable average values of concentration, strength, and resonance wavelength of the oscillators. It has to be taken into account that all of these quantities can change with the temperature. Consequently, one obtains for the temperature coefficient [2]

$$
\frac{\mathrm{dn}(\lambda, \mathrm{T})}{\mathrm{d} T}=\frac{\mathrm{n}^{2}(\lambda, \mathrm{T})-1}{2 \mathrm{n}(\lambda, \mathrm{T})}\left[\mathrm{D}(\mathrm{T})+\frac{\mathrm{E}(\mathrm{T})}{\lambda^{2}-\lambda_{0}{ }^{2}(\mathrm{~T})}\right]
$$

with

$$
\mathrm{D}(\mathrm{T})=\frac{\mathrm{d}}{\mathrm{dT}} \ln (\mathrm{V})+\frac{\mathrm{d}}{\mathrm{dT}} \ln (\mathrm{f})+2 \frac{\mathrm{d}}{\mathrm{d} T} \ln \left(\lambda_{0}\right)
$$

and

$$
\mathrm{E}(\mathrm{T})=2 \lambda_{0}^{2} \frac{\mathrm{d}}{\mathrm{dT}} \ln \left(\lambda_{0}\right)
$$

Since the functions $\mathrm{D}(\mathrm{T})$ and $\mathrm{E}(\mathrm{T})$ are not known, we use the expansions

$$
\mathrm{D}(\mathrm{T})=\mathrm{D}_{0}+2 \mathrm{D}_{1}\left(\mathrm{~T}-\mathrm{T}_{0}\right)+3 \mathrm{D}_{2}\left(\mathrm{~T}-\mathrm{T}_{0}\right)^{2}
$$

and

$$
\mathrm{E}(\mathrm{T})=\mathrm{E}_{0}+2 \mathrm{E}_{1}\left(\mathrm{~T}-\mathrm{T}_{0}\right)
$$

with $\mathrm{T}_{0}$ being a reference temperature (e.g. $20^{\circ} \mathrm{C}$ ). Furthermore, the temperature dependence of the prefactor $\frac{n^{2}(\lambda, T)-1}{2 n(\lambda, T)}$ in $(6)$ can be neglected. Therefore equation (6) can be simplified further 


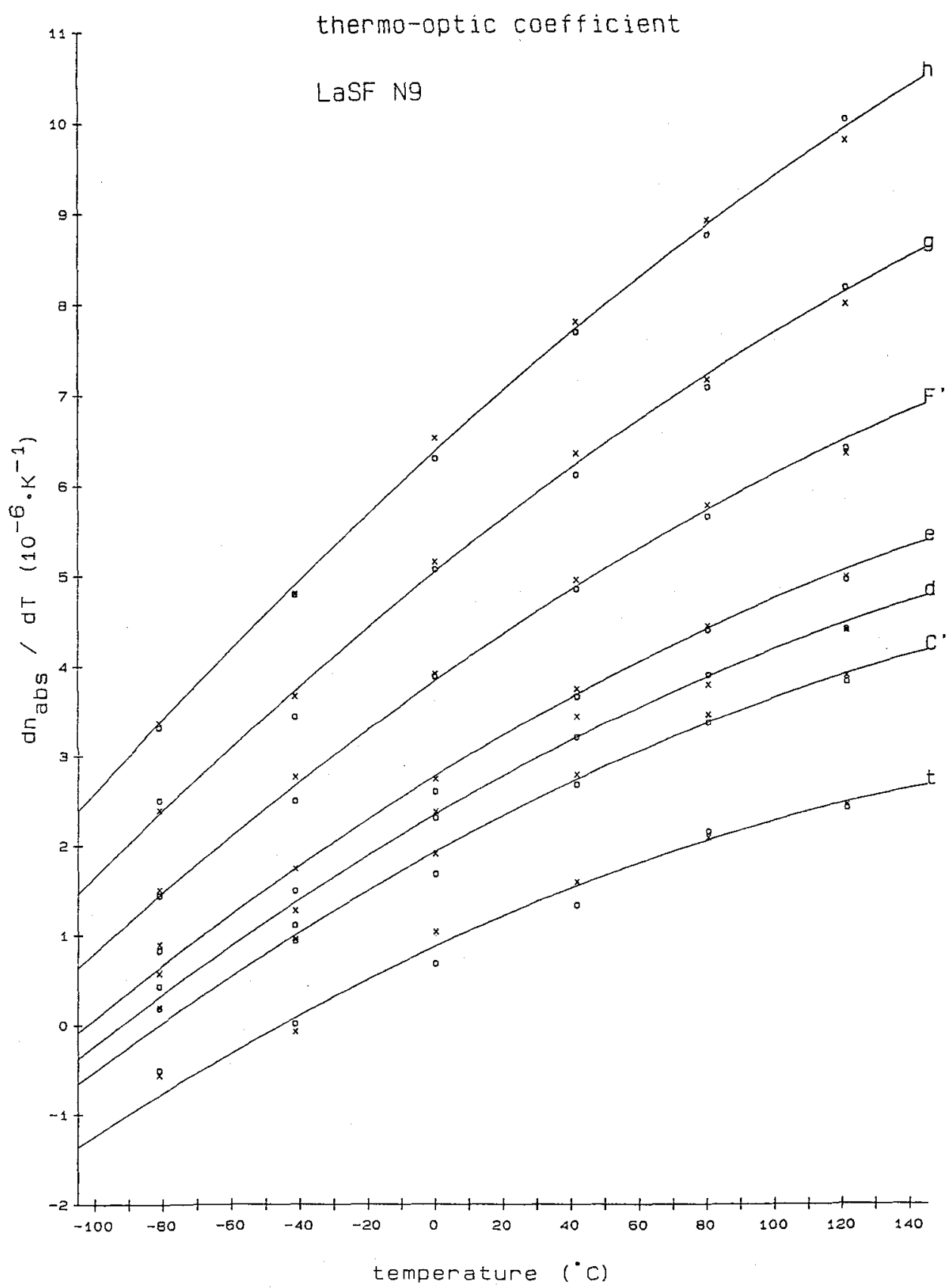

Fig. 1: 'Ihermo-optic coefficient of optical glass type LaSF N9 with respect to vacuum as a function of temperature with the wavelength as a parameter. The full curves represent the results of calculations using equation (9). Wavelengths: $h=404.66 \mathrm{~nm}, g=435.83 \mathrm{~nm}, F^{\prime}=479.99 \mathrm{~nm}$, $\mathrm{e}=546.07 \mathrm{~nm}, \mathrm{~d}=587.56 \mathrm{~nm}, \mathrm{C}^{\prime}=643.85 \mathrm{~nm}, \mathrm{t}=1013.98 \mathrm{~nm}$.

$\mathrm{D}_{0}=-9.44 \cdot 10^{-7} /{ }^{\circ} \mathrm{C}, \quad \mathrm{D}_{1}=1.14 \cdot 10^{-8} /\left({ }^{\circ} \mathrm{C}\right)^{2}, \quad \mathrm{D}_{2}=-1.87 \cdot 10^{-11} /\left({ }^{\circ} \mathrm{C}\right)^{3}, \quad \mathrm{E}_{0}=9.22 \cdot 10^{-7} /{ }^{\circ} \mathrm{C}$, $\mathrm{E}_{1}=1.22 \cdot 10^{-9} /\left({ }^{\circ} \mathrm{C}\right)^{2}, \lambda_{0}=255 \mathrm{~nm}$

$\mathrm{n}\left(\lambda, 20^{\circ} \mathrm{C}\right)=3.2994326-1.1680436 \cdot 10^{-2} \mu \mathrm{m}^{-2} \cdot \lambda^{2}+4.0133103 \cdot 10^{-2} \mu \mathrm{m}^{2} \cdot \lambda^{-2}+$

$+1.3263988 \cdot 10^{-3} \mu \mathrm{m}^{4} \cdot \lambda^{-4}+4.7438783 \cdot 10^{-4} \mu \mathrm{m}^{6} \cdot \lambda^{-6}+7.8507188 \cdot 10^{-5} \mu \mathrm{m}^{8} \cdot \lambda^{-8}$ 
to $\quad \frac{\operatorname{dn}(\lambda, T)}{\mathrm{dT}}=$

$$
\frac{\mathrm{n}^{2}\left(\lambda, \mathrm{T}_{0}\right)-1}{2 \mathrm{n}\left(\lambda, \mathrm{T}_{0}\right)}\left[\mathrm{D}_{0}+2 \mathrm{D}_{1}\left(\mathrm{~T}-\mathrm{T}_{0}\right)+3 \mathrm{D}_{2}\left(\mathrm{~T}-\mathrm{T}_{0}\right)^{2}+\frac{\mathrm{E}_{0}+2 \mathrm{E}_{1}\left(\mathrm{~T}-\mathrm{T}_{0}\right)}{\lambda^{2}-\lambda_{0}{ }^{2}}\right]
$$

The parameters $\mathrm{D}_{0}, \mathrm{D}_{1}, \mathrm{D}_{2}, \mathrm{E}_{0}, \mathrm{E}_{1}$, and $\lambda_{0}$ have to be determined by a fitting routine applied to data determined experimentally according to equation (3). On the other hand, equation (9) can be integrated to yield the increments or decrements $\Delta n(\lambda, T)$ as a function of the wavelength and temperature. In this case, the coefficients can be determined directly by a fit of the experimental increments and decrements $\Delta \mathrm{n}\left(\lambda_{\mathrm{k}}, \mathrm{T}_{\mathrm{j}}\right)$.

Fig. 1 shows as an example experimental data points together with the fit (full curves) by equation (9) for the optical glass LaSF N9. In fact, the fit is rather convincing. Data of the thermo-optic coefficient are available for many optical glasses in ref [3].

\section{Variations of the refractive index due to thermal treatment of glasses.}

Optical glasses have to be annealed very carefully in order to avoid thermal stresses and inhomogeneities [4-8]. Among a large variety of possible annealing schedules one prefers the annealing with a constant cooling rate for technical and economical reasons. One starts to anneal the glass at a constant rate from temperatures above the tranformation temperature $T_{g}$ to temperatures sufficiently below $\mathrm{T}_{\mathrm{g}}$ where relaxation of the structure and of the properties can be neglected. Very critical is the temperature range near $T_{g}$, since some properties depend on the annealing rate in that range. This effect can be used in order to adjust the refractive index by adjusting the annealing rate if necessary. The change of the refractive index $n_{d}$ at wavelength $\mathrm{d}=587.56 \mathrm{~nm}$ as a function of the annealing rate $\mathrm{v}$ is represented by the empirical relation [6-8]

$$
\Delta \mathrm{n}_{\mathrm{d}}(\mathrm{v})=\mathrm{m}_{\mathrm{d}} \ln \left(\mathrm{v} / \mathrm{v}_{0}\right)
$$

with the reference annealing rate $\mathrm{v}_{0}$ and the parameter $\mathrm{m}_{\mathrm{d}}$ which depends on the type of glass. In general, $\mathrm{n}_{\mathrm{d}}$ decreases with increasing annealing rate.

Relation (10) diverges in the limits $\mathrm{v} \rightarrow 0$ and $\mathrm{v} \rightarrow \infty$. Therefore it cannot be applied in these cases. In practice, however, these limits are not relevant, because for $\mathrm{v} \rightarrow 0$ the annealing rates are impractically slow and for $\mathrm{v} \rightarrow \infty$ the temperature gradients in the samples become too large.

The changes of $n$ are related to a different degree of relaxation and change of the nearestneighbor-order, which depend on the annealing rate. In addition to the density of oscillators (which relates to the mass density), their oscillator strengths and resonance wavelengths depend on the nearest-neighbor-order as well. Consequently, besides the refractive index $\mathrm{n}_{\mathrm{d}}$ one can also modify to a small extent the Abbe numbers

$$
\nu_{\mathrm{d}}=\frac{\mathrm{n}_{\mathrm{d}}-1}{\mathrm{n}_{\mathrm{F}}-\mathrm{n}_{\mathrm{C}}}
$$

of the optical glasses by a change of the annealing rate starting at temperatures above $\mathrm{T}_{\mathrm{g}}$. For a given type of glass, however, $\mathrm{n}_{\mathrm{d}}$ and $\nu_{\mathrm{d}}$ cannot be modified independently.

An important question for practical applications is whether changes of the refractive index can be induced by annealing below $\mathbf{T}_{\mathbf{g}}$ due to thermal treatment during the production of optical elements. Since lenses may be subjected to temperatures well above 200 or even $300^{\circ} \mathrm{C}$ during coating processes with subsequent annealing at a rate much faster than the rate during the production of the glass, such possible changes of $n$ have been investigated. The experimental procedure and the results have been described in [9]. In all cases, $n_{d}$ decreased due to the fast annealing rate. This corresponds to the expectation. Important for applications is the observation that glasses with large content of $\mathrm{Ti}_{2}$ show a rather large decrease of $\mathrm{n}_{\mathrm{d}}$ upon fast annealing. Fig. 2.

Even the dispersion can be changed by the fast annealing process below $T_{g}$ as can be seen in 


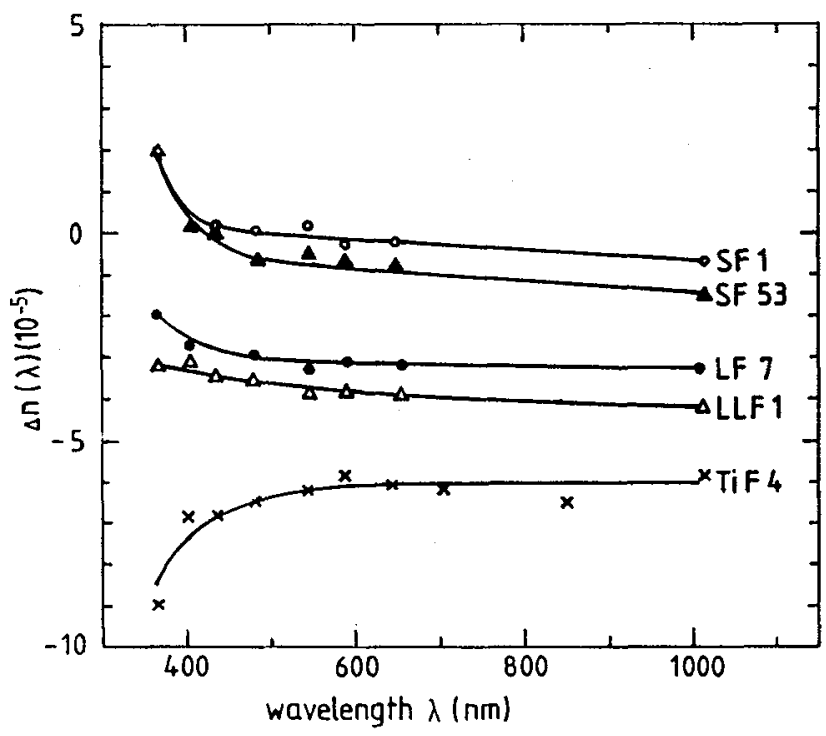

Fig. 2:

Changes of the refractive indices $\Delta \mathrm{n}$ as a function of wavelength after thermal cycling of different optical glasses (heating to $250^{\circ} \mathrm{C}$ for 30 minutes and subsequent fast annealing).

\section{The stress-optical coefficient}

Annealed isotropic glasses become optically anisotropic for linearly polarized electromagnetic waves if mechanical stress is applied. Fig. 3 shows schematically a rectangular parallelepiped of glass with the uniaxial stress $\sigma$ applied uniformly to two opposite surfaces. In this case, the refractive index depends on the orientation of the electric field vector of the electromagnetic wave with respect to the direction of the stress $\sigma$. If the electric field vector of the wave is parallel or antiparallel to $\sigma$, the refractive index $n$ changes into $n+\Delta n_{11}$. For an electromagnetic wave with the field vector perpendicular to $\sigma$ it changes into $n+\Delta n_{\perp}$. The changes $\Delta n_{11}$ and $\Delta n_{\perp}$ can be determined as a function of $\sigma$ by interferometric methods $[10,11]$. Since $\Delta \mathrm{n}_{11}$ and $\Delta \mathrm{n}_{\perp}$ are proportional to $\sigma$ over a large range, one prefers to determine

$$
\mathrm{K}_{11}=\frac{\mathrm{dn}}{\mathrm{d} \sigma} \text { and } \mathrm{K}_{\perp}=\frac{\mathrm{dn}}{\mathrm{d} \sigma}
$$

Experimental data of these quantities are available for many optical glasses from refs. $[11-14]$.

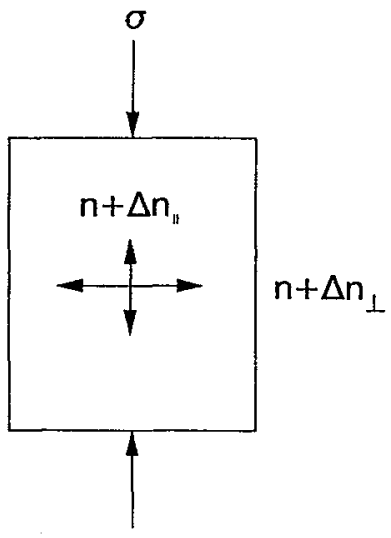

Fig. 3:

Orientation of the stress $\sigma$ and the limiting cases of the refractive index. 
Mostly, $K_{11}$ and $K_{\perp}$ are given for single wavelengths in the visible spectral region (e.g. $\lambda_{D}=589.3$ $\mathrm{nm})$. The largest values for optical oxide glasses determined recently are $\mathrm{K}_{11}=-9 \cdot 10^{-6} \mathrm{~mm}^{2} / \mathrm{N}$ and $\mathrm{K}_{\perp}=-7.6 \cdot 10^{-6} \mathrm{~mm}^{2} / \mathrm{N}$ for glass type SF 59 [12]. Thus, stresses in the order of some $\mathrm{N} / \mathrm{mm}^{2}$ or MPa can cause absolute changes of the refractive index in the 5. decimal place.

In order to detect and evaluate stresses in glasses, it is more convenient to determine the anisotropy or birefringence $n_{11}-n_{\perp}$ directly instead of measuring the changes $\Delta n_{11}$ and $\Delta n_{\perp}$ separately $[15,16]$. In this case, one uses the stress-optical coefficient

$$
\mathrm{K}=\frac{\mathrm{dn}}{\mathrm{d} \sigma}-\frac{\mathrm{dn}}{\mathrm{d} \sigma}=\mathrm{K}_{11}-\mathrm{K}_{\perp}
$$

Recently, a dispersion formula has been developed for $\mathrm{K}$. It has been derived along the same lines as for the temperature coefficient of the refractive index in section 2. Assuming that in the one-term Sellmeier equation (5) the density N/V, the strength $f$, and the mean resonance wavelength $\lambda_{0}$ of the oscillators are changed by the stress $\sigma$ according to the specific directions parallel or perpendicular to $\sigma$ we obtain

$$
\mathrm{K}(\lambda)=\frac{\mathrm{dn}_{\mathrm{H}}}{\mathrm{d} \sigma}-\frac{\mathrm{dn}}{\mathrm{d} \sigma}=\frac{\mathrm{n}^{2}(\lambda)-1}{2 \mathrm{n}(\lambda)}\left[\mathrm{A}+\frac{\mathrm{B}}{\lambda^{2}-\lambda^{2}{ }_{\text {soc }}}\right]
$$

with the fitting parameters $\mathrm{A}, \mathrm{B}$, and $\lambda_{\text {soc. }}$.

Figs. $4 \mathrm{a}$ and $\mathrm{b}$ show examples of experimental results (data points) together with the results of a fitting procedure (full curves) using equation (14). In many cases, the fitting parameter $B$ can be assumed to be zero. In this case, the slight dispersion of $K(\lambda)$ is very well described by the prefactor $\left[n^{2}(\lambda)-1\right] /[2 n(\lambda)]$ in (14). For high lead content glasses, however, the dispersion is reversed and more pronounced. Then, the dispersion term $B /\left(\lambda^{2}-\lambda_{0}{ }^{2}\right)$ in (14) cannot be neglected any more as can be seen in Fig. $4 \mathrm{~b}$ for the glass types SF 1, SF 14, SF 18, SF 55 , and SF 57.

In most cases $K>0$, corresponding to $K_{11}>K_{\perp}$. With increasing content of lead oxide, however, $K_{\perp}$ becomes larger than $K_{11}$, which results in $K(\lambda)<0$ for the very high lead content glasses
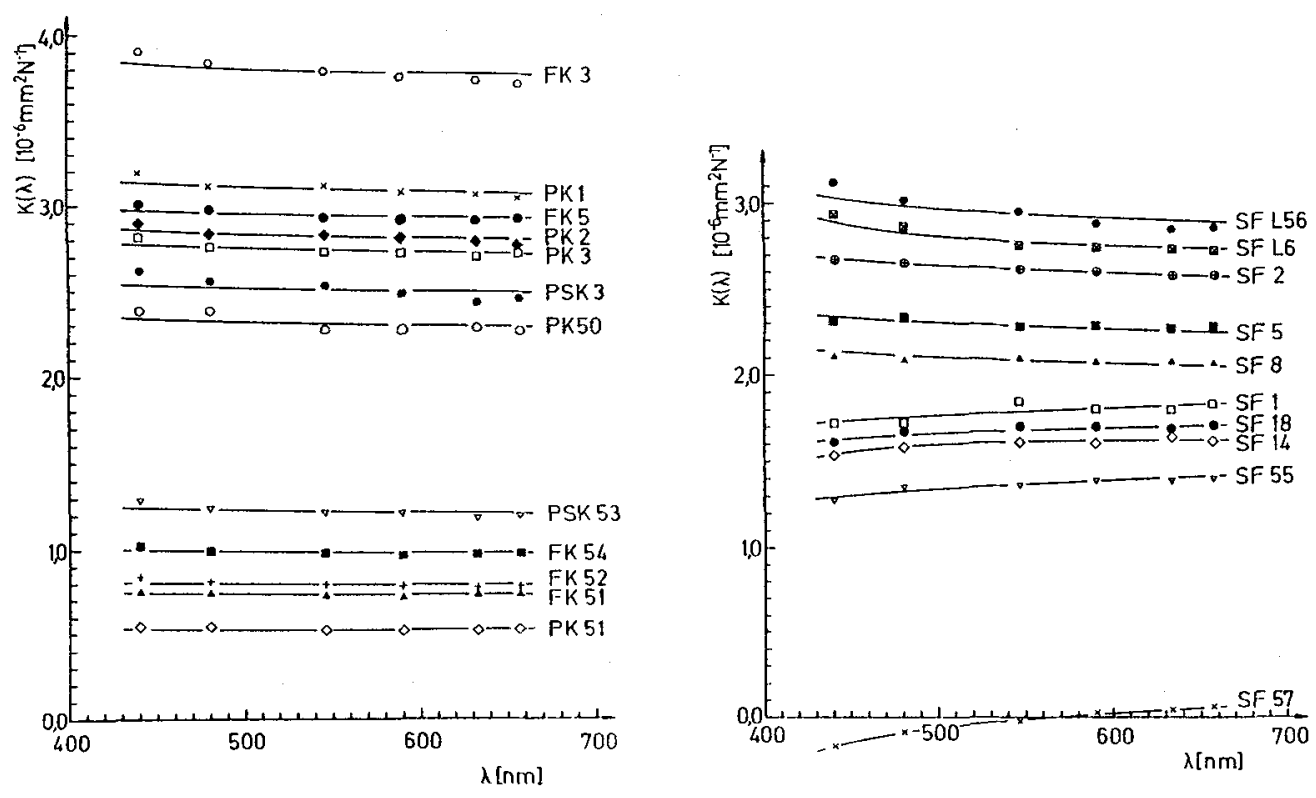

Fig. 4 a and $b$ :

Stress - optical coefficient as a function of wavelength $\lambda$ at $20^{\circ} \mathrm{C}$ for optical glasses. 
SF 58 and SF 59 (not shown in Fig. $4 \mathrm{a}$ and b). For a given concentration of lead oxide, which depends on the content of the other components, we have $K \approx 0$ (see the data for $S F 57$ in Fig. $4 \mathrm{~b}$ ). Such a glass does not show appreciable stress-induced birefringence. To honour the scientist who first described the composition of such a glass [17] it is named "Pockels' glass".

\section{The electro-optic effect in glasses (Kerr effect)}

Electric fields can induce in homogeneous glasses anisotropies for linearly polarized electromagnetic waves, too. The configuration to induce uniaxial anisotropy is similar to that in Fig. 3 except that the uniaxial mechanical stress $\sigma$ is replaced by an electric field of strength $\overrightarrow{\mathrm{E}}$. This anisotropy increases with the square of the absolute value of $\vec{E}$. Since the changes $\Delta n_{11}$ and $\Delta \mathrm{n}_{\perp}$ are small, one determines experimentally the difference $\mathrm{n}_{11}-\mathrm{n}_{\perp}$ rather than $\Delta \mathrm{n}_{11}$ and $\Delta \mathrm{n}_{\perp}$ separately. One might prefer to express the birefringence by a relation

$$
\mathrm{n}_{\mathbf{1 1}}-\mathrm{n}_{\perp}=\mathrm{K}_{\mathrm{k}} \mathrm{E}^{2}
$$

For historical reasons, however, one uses the relation

$$
\mathrm{n}_{11}-\mathrm{n}_{\perp}=\lambda \mathrm{B}_{\mathrm{k}} \mathrm{E}^{2}
$$

with the Kerr constant $B_{k}$

For oxide glasses, the absolute value of $B_{k}$ is in the order of 0.1 to $3 \cdot 10^{-12} \mathrm{~cm} / \mathrm{V}^{2}$, whereas for chalcogenide glasses it is much larger, e.g. $8.7 \cdot 10^{-12} \mathrm{~cm} / \mathrm{V}^{2}$ for glassy $\mathrm{As}_{2} \mathrm{~S}_{3}[18-21]$.

Since $B_{k}$ is in the order of $10^{-12} \mathrm{~cm} / V^{2}$ for oxide glasses, one estimates a field strength larger than $10^{5} \mathrm{~V} / \mathrm{cm}$ in order to induce a birefringence of about $10^{-6}$ in the visible spectral region. Because such a large field strength is necessary to change $n$ of glasses appreciably, this effect has not found much interest for applications until now.

The Kerr constant shows dispersion [19,21]. Its value decreases with increasing wavelength in the visible spectral range. A detailed analysis of the dispersion is still to be done; one expects that for $K_{k}=\lambda \cdot B_{k}$ an analysis similar to that of the stress-optical coefficient is valid and leads to a dispersion formula of the type (14).

\section{Magneto-optic effects in glasses}

Besides electric fields, also magnetic fields interact with electromagnetic waves in matter. Two limiting configurations are obvious. By analogy with the Kerr effect the electromagnetic wave propagates perpendicular to the magnetic field. This is the configuration of the CottonMouton effect. In this case, the magnetic field induces a birefringence for linearly polarized electromagnetic waves

$$
\mathrm{n}_{11}-\mathrm{n}_{\perp}=\lambda \mathrm{K}_{\mathrm{KM}} \mathrm{B}^{2}
$$

with the absolute value $\mathrm{B}$ of the magnetic flux density vector and the Cotton-Mouton coefficient $\mathrm{K}_{\mathrm{KM}}$. Data of $\mathrm{K}_{\mathrm{KM}}$, however, are not available for glasses but for gases and liquids [22].

Much more important for applications is the Faraday configuration (see Fig. 5). In this case, a linearly polarized electromagnetic wave propagates in the glass parallel (or antiparallel) to the magnetic flux density vector $\vec{B}$ which causes the plane of vibration of the wave to rotate. The angle of rotation $\alpha$ is given by

$$
\alpha=\mathrm{V} \ell \mathrm{B}
$$

with the absolute value $B$ of the magnetic flux density, the distance $\ell$ the wave traveled in the sample, and the Verdet constant $\mathrm{V}$. The sign of $\mathrm{V}$ - and thus of the rotation angle - is positiv (negative), if the rotation is clockwise (counterclockwise) looking parallel to the vector of the magnetic flux density irrespective of the direction of the propagation of the electromagnetic wave 


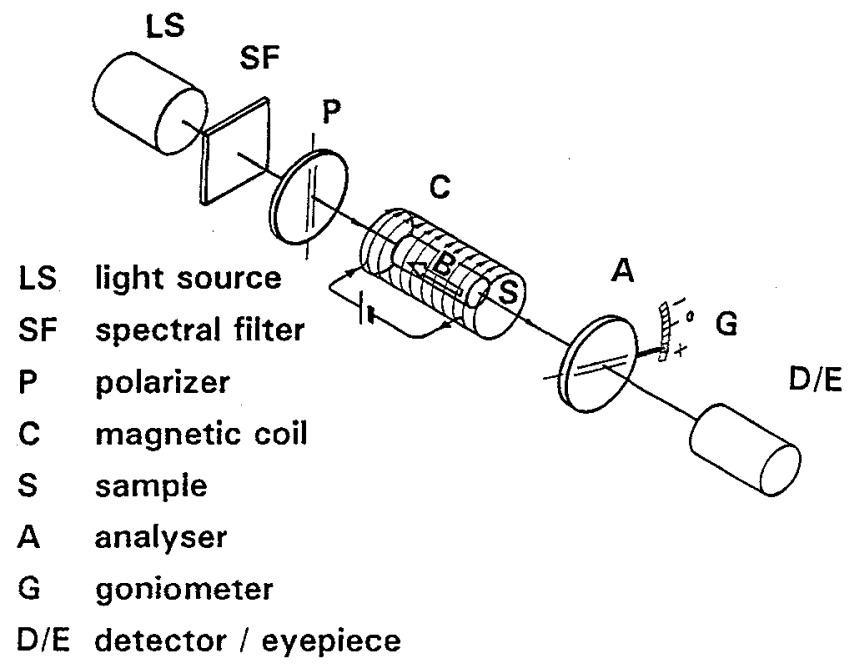

Fig. 5:

Experimental set-up for measuring the Faraday rotation angle.

being parallel or antiparallel to $\overrightarrow{\mathrm{B}}$. Positive Verdet constants correspond to diamagnetic materials, whereas $\mathrm{V}$ is negative for paramagnetics.

In conjunction with linear polarizers the Faraday rotation can be exploited to modulate the intensity of linearly polarized light and to construct optical isolators, which transmit electromagnetic waves in one direction, only, whereas they are blocking in the reverse direction. This effect is useful to suppress the interaction of the reflected laser beam with the laser itself or with other components.

Linearly polarized waves can be represented as a superposition of left- and right-handed circularly polarized waves. If there is a phase-shift induced between the left- and right-handed polarized wave, the superposition yields a linearly polarized wave of which the plane of vibration, however, is rotated. Consequently, the Faraday rotation is the result of a birefringence for circularly polarized waves, which is induced by magnetic fields. Thus, the Verdet constant can be rewritten as

$$
V=\frac{\pi}{\lambda}\left\{\frac{d n_{+}(B)}{d B}-\frac{d n_{-}(B)}{d B}\right\}
$$

wherein $n_{+}(B)$ and $n_{-}(B)$ are the refractive indices for right- and left-handed electromagnetic waves a a function of the magnetic flux density.

On the basis of the single oscillator model (equation (5)) for $n(\lambda)$ the following dispersion formula for the Verdet constant has been derived [23]

with

$$
\begin{gathered}
\mathrm{V}=\frac{\pi}{\lambda}\left\{\frac{\mathrm{n}^{2}-1}{2 \mathrm{n}}\right\}\left\{\mathrm{k}_{1}+\frac{\mathrm{k}_{2}}{\lambda^{2}-\lambda_{0}^{2}}\right\} \\
\mathbf{k}_{1}=\frac{\mathrm{d}\left(\ln \mathrm{f}_{+}-\ln \mathrm{f}_{-}\right)}{\mathrm{dB}}+2 \frac{\mathrm{d}\left(\ln \lambda_{0+}-\ln \lambda_{0-}\right)}{\mathrm{dB}} \\
\mathrm{k}_{2}=2 \lambda_{0}^{2} \frac{\mathrm{d}\left(\ln \lambda_{0+}-\ln \lambda_{0-}\right)}{\mathrm{dB}}
\end{gathered}
$$

and

wherein $f_{t}, f_{-}, \lambda_{0+}$ and $\lambda_{0 \text { - }}$ are the mean oscillator strength and resonance wavelength for rightand left-handed circularly polarized waves. For a vanishing magnetic field, obviously $f_{+}=f_{-}=f$ and $\lambda_{0+}=\lambda_{0-}=\lambda_{0}$. 

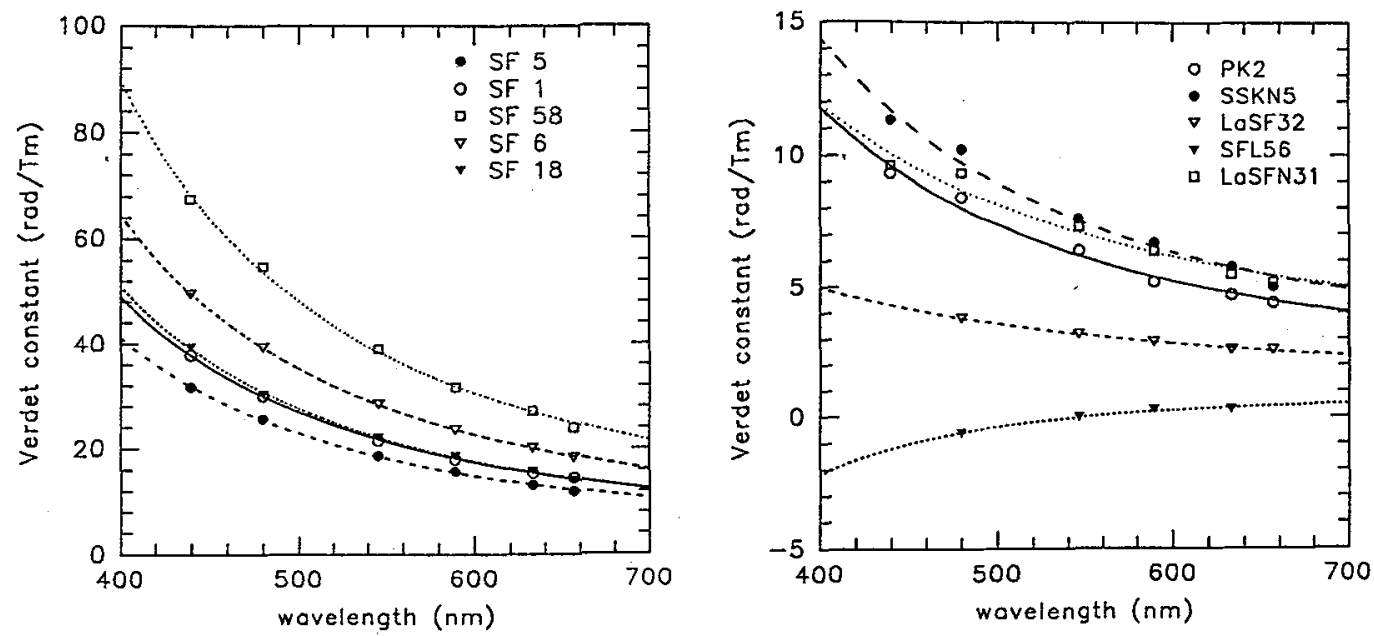

Fig. 6 a and $b$ :

The Verdet constant $V$ of different optical glasses as a function of wavelength in the visible spectral range. Experimental results are shown by the data points and the curves represent the results of fitting calculations according to equation (21).

Equation (20) can be simplified further to

$$
\mathrm{V}=\frac{\pi}{\lambda}\left\{\mathrm{a}+\frac{\mathrm{b}}{\lambda^{2}-\lambda_{0 \mathrm{v}}^{2}}\right\}
$$

with the fitting parameters $a, b, \lambda_{0 v}$.

Experimental results of the Verdet constant as a function of wavelength are shown in Fig. 6 by the data points. The curves represent the results of a fitting procedure using equation (21). The largest Verdet constants of Fig. 6 are observed for glasses with the largest content of $\mathrm{PbO}$. On the other hand, glasses with $\mathrm{V} \approx 0$ at room temperature have also been investigated (see e. g. type SFL 56 in Fig. 6 b). These types of glass do not show appreciable Faraday rotation at that temperature. One can conclude that the diamagnetic behavior is compensated by the influence of small amounts of paramagnetic ions in these glasses.

\section{Further possibilities}

In the preceding sections, the most prominent differential modifications of the refractive index $\mathrm{n}(\lambda)$ of glasses have been discussed. Because of lack of space, further possibilities shall be mentioned briefly at least.

UV-and $\gamma$-irradiation as well as $\alpha$ and $\beta$ particles or neutrons and implanted ions can change the structure of the glass and thus the refractive index [24-26]. Any transfer of charge into different sites in the glassy matrix or even into excited states as well as charge injection can induce a change of $n[27-29]$.

The non-linearities induced by high photon densities became very important in the recent decades. In this case, $\mathrm{n}$ can vary with the intensity I of an electromagnetic wave itself which is taken into account by the non-linear refractive index $\gamma$ according to

$$
\mathrm{n}(\mathrm{I}, \lambda)=\mathrm{n}(\mathrm{I}=0, \lambda)+\gamma \mathrm{I}
$$

Since $\mathrm{I} \sim \mathrm{E}^{2}$ one can compare (22) with (16). Thus, the intensity dependent part of the refractive index $\gamma \cdot I$ is due to a degenerate electro-optic or Kerr effect with the frequencies of the applied electric field and of the electromagnetic wave being the same. 


\section{Acknowledgment}

I thank Werner W. Jochs and his coworkers as well as Dipl.-Phys. G. Przybilla and Dipl.-Phys. G. Westenberger for the help providing the experimental results.

\section{References}

[1] Optical Glass Catalogue 3111E, Schott Glaswerke, Mainz, Fed. Rep. Germany

[2] H. J. Hoffmann, W. W. Jochs, and G. Westenberger: SPIE 1327, $219-231$ (1990)

[3] Technical Information No. 19: Dispersion Formula for the Temperature Coefficient of the Refractive Index of Glasses, Schott Glaswerke, Mainz, Fed. Rep. Germany (1988)

[4] L. Prod'homme: Verres et Réfractaires 11, $351-369$ (1957) and Verres et Réfractaires 12, 3-22 (1958)

[5] F. Reitmayer and E. Schuster: Appl. Opt. 11, $1107-1111$ (1972)

[6] H. R. Lillie and H. N. Ritland: J. Am. Ceram. Soc. 37, 466 - 473 (1954)

[7] H. Rötger and H. Besen: Feingerätetechnik 10, 547 - 554 (1961)

[8] H. Rötger and H. Besen: Silikattechnik 13, 424-427 (1962)

[9] H. J. Hoffmann, W. W. Jochs, and N. M. Neuroth: SPIE 970, 2 - 9 (1989)

[10] N. F. Borrelli and R. A. Miller: Appl. Opt. 7, 745 - 750 (1968)

[11] Erich Schuster and Franz Reitmayer: Glastechn. Ber. 34, 130 - 133 (1961)

[12] Technical Information No. 20: Änderungen der Brechzahlen optischer Gläser durch Zugund Druckbelastungen, Schott Glaswerke, Mainz, Fed. Rep. Germany (1988)

[13] O. Lindig: Spannungsdoppelbrechung in Gläsern, p. 3-542 in Landolt-Börnstein II/8, Springer-Verlag, Berlin (1962)

[14] Clemens Schaefer and Heinrich Nassenstein: Z. Naturforschung 8a, 90-96 (1953)

[15] Technical Information No. 15: Der spannungsoptische Koeffizient optischer Gläser, Schott Glaswerke, Mainz, Fed. Rep. Germany (1984)

[16] T. N. Vasudevan and R. S. Krishnan: J. Phys. D: Appl. Phys. 5, $2283-2287$ (1972)

[17] F. Pockels: Ann. Phys. (Leipzig) 7, 745 - 771 (1902)

[18] M. Paillette: Opt. Commun. 4, $292-295$ (1971)

[19] M. Paillette: Opt. Commun. 13, 64-67 (1975)

[20] N. F. Borrelli: Phys. Chem. Glasses 12, $93-96$ (1971)

[21] O. D. Tauern: Ann. Physik, IV Folge, 32, 1064 - 1084 (1910)

[22] Landolt-Börnstein: II. Band: Eigenschaften der Materie in ihren Aggregatzuständen. 8. Teil: Optische Konstanten. Springer-Verlag, Berlin (1962)

[23] G. Westenberger, H. J. Hoffmann, W. W. Jochs, and G. Przybilla: SPIE 1535, 113-120 (1991)

[24] A. P. Webb and P. D. Townsend: J. Phys. D 9, $1343-1354$ (1976)

[25] S. Gebala and I. Wilk: Opt. Appl. 12, $483-488$ (1982)

[26] G. V. Byurganovskaya, B. I. Kisin and N. F. Orlov: Sov. J. Opt. Technol. 34, 167 - 173 (1967)

[27] G. D. Baldwin and E. P. Riedel: J. Appl. Phys. 38, 2726 - 2738 (1967)

[28] Frederic M. Durville and Richard C. Powell: J. Opt. Soc. Am. B 4, $1934-1937$ (1987)

[29] A. F. Evans and D. G. Hall: Appl. Phys. Lett. 56, $212-214$ (1990) 